\title{
HUBUNGAN KEKERABATAN FENETIK 7 SPESIES JERUK DI DATARAN TINGGI BENER MERIAH
}

\author{
Aulia Agustina ${ }^{1}$, Hasanuddin $^{2}$, Cut Nurmaliah ${ }^{3}$ \\ Jurusan Pendidikan Biologi, FKIP Universitas Syiah Kuala \\ auliaagustina@gmail.com \\ hasanuddin@fkip.unsyiah.ac.id
}

\begin{abstract}
ABSTRAK
Kajian "Hubungan Fenetik 7 Jenis Tanaman Jeruk di Dataran Tinggi Bener Meriah" dilaksanakan pada bulan Agustus hingga September 2017. hubungan 7 jenis tanaman jeruk di dataran tinggi Bener Meriah. Metode yang digunakan dalam penelitian ini adalah observasi dengan jenis campuran antara kualitatif dan kuantitatif. Subyek penelitian ini adalah 7 jenis tanaman jeruk, yaitu: a) Citrus reticulata; b) jeruk amblycarpa; c) Citrus hystrix; d) Jeruk nobilis; e) jeruk maksimal; f) Jeruk sinensis; dan g) Jeruk aurantifolia. Parameter penelitian ini adalah karakteristik morfologi batang, daun, buah dan bunga. Data yang terkumpul dianalisis secara deskriptif, dimana kesamaan diukur dengan menggunakan Indeks Kesamaan (SI) dan ketidaksamaan diukur dengan menggunakan Indeks Ketidaksamaan (DI) untuk mengklasifikasikan total 7 spesies tanaman jeruk menggunakan analisis klaster. Berdasarkan ciri morfologinya dapat disimpulkan bahwa terdapat beberapa perbedaan dan persamaan diantara 7 jenis tanaman jeruk yang terdapat di Kabupaten Bener Meriah. Kombinasi Citrus hystrix dengan Citrus aurantifolia memiliki hubungan fenetik yang paling dekat, yaitu memiliki SI sebesar 66. Kombinasi lain yang juga memiliki hubungan fenetik yang erat adalah Citrus hystrix dengan Citrus maxima dan Citrus nobilis dengan Citrus sinensis. Kekerabatan yang memiliki DI tertinggi adalah kombinasi Citrus amblycarpa dengan Citrus maxima yang memiliki 88 DI.
\end{abstract}

Kata Kunci: Hubungan Fenetik, Rutaceae, 7 Spesies Jeruk.

\section{ABSTRACT}

The study about "Phenetic Relationship of 7 Species of Orange Plants in BenerMeriah Highlands" was inducted back in August until September 2017. The aim of this study is to describe the morphological characterization of 7 species of orange plants in BenerMeriah highlands and to understand the phenetic relationship of 7 species of oranges plant in BenerMeriah highlands. The method used in this study was observation with the type of mixture between qualitative and quantitative. The subjects of this study are 7 species of orange plants, namely: a) Citrus reticulata; b) Citrus amblycarpa; c) Citrus hystrix; d) Citrus nobilis; e) Citrus maxima; f) Citrus sinensis; and g) Citrus aurantifolia. The parameters of this study were the morphological characteristic of stems, leaves, fruits and flowers. The collected data were analyzed descriptively, where the similarities were measured using Similarity Index (SI) and the dissimilarities were measured using Dissimilarity Index (DI) to classify the total of 7 species of orange plants using cluster analysis. According to the morphological characteristics, it could be concluded that there are several differences and similarities among the 7 species of orange plants found in BenerMeriah Regency. The combination of Citrus hystrix with Citrus aurantifolia have the 
closest phenetic relationship, which have 66 of SI. The other combinations that also have close phenetic relationship are Citrus hystrix with Citrus maxima and Citrus nobilis with Citrus sinensis. The pheneticrelationship that have the highest DI is the combination of Citrus amblycarpa with Citrus maxima, which have 88 of DI.

Keyword: Phenetic Relationship, Rutaceae, 7 SpeciesCitrus.

\section{PENDAHULUAN}

Hubungan kekerabatan antar tumbuhan dapat dilihat dari seberapa banyak ciri yang sama. Semakin banyak ciri yang sama yang dimiliki oleh suatu tumbuhan maka semakin dekat hubungan kekerabatannya dan semakin banyak perbedaan yang dimiliki oleh suatu tumbuhan maka semakin jauh hubungan kekerabatannya. Kajian kekerabatan dapat di kelompokan menjadi dua antara lain hubungan kekerabatan secara fenetik, dan hubungan kekerabatan secara filogenetik. Fenetik merupakan pengkajian kekerabatan antar makhluk hidup berdasarkan ciri morfologi. Sedangkan filogenetik mengkaji hubungan kekerabatan melalui kajian evolusi dari setiap jenis. Kedua bidang tersebut baik fenetik maupun filogenetik memerlukan sejumlah pengamatan ciri yang diteliti (Radford, 1986).

Ciri morfologi tumbuhan mudah untuk diamati. Hal ini menyebabkan ciri morfologi dijadikan sebagai dasar klasifikasi tumbuhan (Rideng,1986). Dalam pengamatan tumbuhan, minimal ciri morfologi yang diamati adalah sebanyak 50 ciri. Adapun ciri-ciri morfologi yang digunakan dalam klasifikasi tumbuhan ialah bagian vegetatif dan generatif, dimana pengamatan bagian vegetatif terdiri atas, ada tidaknya jaringan pembuluh, macam daun, kedudukan daun, dan ciri organ lainnya (Tjitrosomo,2007). Lebih lanjut Gotto (1982) mengungkapkan bahwa semakin banyaknya kesamaan ciri yang dimiliki oleh sejumlah jenis tumbuhan, menunjukkan semakin dekat hubungan kekerabatannya, dan sebaliknya.

Tanaman jeruk adalah tanaman buah annual yang hidup di daerah beriklim tropis, seperti Asia. Tanaman ini dipercaya berasal dari Cina. Tanaman jeruk yang ada di Indonesia diklaim sebagai peninggalan bangsa Belanda (Deptan, 2012). Indonesia dan negara tropis lainnya di Asia sangat cocok dijadikan tempat pembudidayaan jeruk. Hal ini dikarenakan tanaman jeruk dapat tumbuh dengan baik dan wilayah ini merupakan habitat asal tumbuhan ini (Aak, 1994).

Bener Meriah merupakan salah satu Kabupaten yang terdapat di Provinsi Aceh. Bener Meriah merupakan Kabupaten yang kaya akan potensi alamnya, khususnya 
dibidang pertanian, perikanan, peternakan dan pertambangan. Komoditas pertanian yang utama dari daerah ini adalah tanaman buah jeruk, alpukat, tomat, kopi dan cabai.

Spesies tanaman jeruk di Kabupaten Bener Meriah terdiri dari beberapa jenis, akan tetapi tanaman jeruk yang dibudidayakan di daerah tersebut adalah jeruk keprok. Jeruk keprok merupakan tanaman hortikultura yang menjadi produk unggulan daerah tersebut. Keunggulan jeruk ini terdapat pada rasanya yang manis dan ukuran yang lebih besar dibandingkan dengan jeruk lokal lainnya (Wienfarid, 2011).

Berdasarkan hasil survei awal jeruk di Bener Meriah memiliki 7 spesies meskipun dalam satu familia yang sama dan genus yang sama, namun setiap spesiesnya memiliki ciri yang berbeda satu dengan yang lainnya. Hal ini juga menyebabkan penulis ingin meneliti lebih lanjut "Hubungan kekerabatan Fenetik 7 Spesies Jeruk Di Dataran Tinggi Bener Meriah".

\section{METODE PENELITIAN}

Objek dari penelitian ini adalah 7 spesies jeruk dari dataran tinggi Bener Meriah, yang mana pengambilan 7 spesies jeruk tersebut dilakukan di dataran tinggi Bener Meriah, dengan mengobservasi langsung ke lokasi penelitian,. Sedangkan untuk menganalisis karakteristik morfologi dan pengamatan tipe stomata pada dilakukan di Laboratorium FKIP Biologi Unsyiah pada bulan Agustus sampai bulan September 2017.

Lebih lanjut, penelitian ini menggunakan pendekatan kualitatif dan kuantitatif, yang mana data berasal dari ciri morfologi yang dimiliki oleh ke 7 spesies jeruk tersebut dianalisis secara deskriptif. Parameter pengamatan morfologi tumbuhan berpusat pada organ batang, daun, bunga, buah dan tipe stomata. Kemudian selain mendeskripsikan morfologi, penelitian ini juga mencari hubungan kekerabatan 7 spesies jeruk tersebut. Analisis hubungan kekerabatan dilakukan dengan menggunakan metode cluster, yaitu dengan mencari Indeks Similaritas (IS) dan Indeks Disimilaritas (ID) pada ke 7 spesies tersebut. Adapun rumus yang digunakan untuk menentukan nilai IS dan ID adalah sebagai berikut:

$$
\begin{gathered}
I D=100-\mathrm{IS} \\
I S=\frac{2\left(\sum c\right)}{\left(\sum \mathrm{A}\right)+\left(\sum B\right)} X 100
\end{gathered}
$$

Keterangan :

ID = Indeks Disimilaritas

IS = Indeks Similaritas

$\sum \mathrm{c}=$ Jumlah yang sama pada dua individu yang dibandingkan

$\sum \mathrm{A}=$ Jumlah ciri individu $\mathrm{A}$

$\sum \mathrm{B}=$ Jumlah ciri individu $\mathrm{B}$ 
Dengan nilai IS

$\geq 75$ : Sangat dekat

50-75 : Dekat

25-50 : Tidak dekat

$\leq 25 \quad$ : Sangat tidak dekat

\section{HASIL DAN PEMBAHASAN}

Data hasil penelitian yang diamati terdiri dari dua jenis, yaitu persamaan dan perbedaan ciri morfologi 7 spesies jeruk di dataran tinggi Bener Meriah, kedua yaitu hubungan kekerabatan 7 spesies jeruk tersebut.

\section{A. Persamaan dan Perbedaan Ciri Morfologi 7 Spesies Jeruk Di Dataran Tinggi Bener Meriah}

Hasil pengamatan yang dilakukan terhadap 7 spesies jeruk di Bener Meriah telah ditemukan perbedaan pada parameter yang diamati di tiap-tiap organ (batang, daun, bunga, buah dan stomata). Parameter yang diamati ditentukan berdasarkan sifat yang pada umumnya dimiliki oleh kelompok famili rutacea (jeruk-jerukan).

Parameter organ batang terdiri dari keberadaan dan panjang duri, warna cabang, dan warna batang. Terdapat 4 spesies yang memiliki batang berduri yaitu Citrus amblycarpa, Citrus hystric, Citrus sinensis, dan Citrus aurantifolia. Panjang duri yang lebih dari $0,5 \mathrm{~cm}$ dimiliki oleh spesies Citrus amblycarpa, Citrus hystrix, dan Citrus sinensis. Batang yang berwarna hijau tua dimiliki oleh Citrus reticulata,
Citrus hystrix, Citrus maxima, Citrus sinensis, dan Citrus aurantifolia.

Parameter daun terdiri dari 13 parameter, yaitu ada tidaknya sayap dan tangkai daun, ukuran panjang, lebar tepi, dan ujung daun. Panjang daun yang kurang dari $10 \mathrm{~cm}$ dimiliki oleh Citrus nobilis, Citrus sinensis, dan Citrus aurantifolia. Citrus amblycarpa, Citrus nobilis, Citrus maxima, dan Citrus sinensis memiliki ukuran lebar daun berkisar 5-10 cm. Sedangkan Citrus reticulata, Citrus hystrix, Citrus aurantifolia memiliki ukuran lebar daun berkisar 1-4 cm. Tepi daun rata hanya dimiliki oleh Citrus maxima. Tepi daun bergerigi dimiliki oleh Citrus amblycarpa, Citrus nobilis, dan Citrus sinensis. Tepi daun beringgit dimiliki oleh Citrus hystrix, dan Citrus aurantifolia. Ujung daun meruncing dimiliki oleh Citrus hystrix, Citrus nobilis, dan Citrus maxima, sedangkan ujung daun tumpul dimiliki oleh spesies Citrus reticulata, Citrus amblycarpa, Citrus sinensis dan Citrus aurantifolia. Spesies yang memiliki sayap pada daun dimiliki oleh Citrus hystrix, Citrus maxima, Citrus sinensis, dan Citrus aurantifolia, sedangkan sayap pada tangkai hanya dimiliki oleh spesies Citrus hystrix, Citrus maxima, dan Citrus aurantifolia.

$$
\text { Parameter bunga yang diamati }
$$
terdiri dari letak, ukuran panjang dan lebar mahkota, jumlah kelopak dan mahkota, 
serta jumlah benang sari. Spesies yang memiliki letak bunga di ujung daun dimiliki oleh Citrus hystrix dan Citrus maxima,. Spesies yang memiliki letak bunga di ketiak daun adalah Citrus reticulata, Citrus amblycarpa, Citrus nobilis, Citrus sinensis, dan Citrus aurantifolia. Jumlah kelopak dan mahkota 5 hanya dimiliki oleh spesies Citrus reticulata, Citrus amblycarpa, dan Citrus sinensis, sedangkan 4 spesies lainnya memiliki jumlah kelopak dan mahkota berjumlah 4. Panjang mahkota kurang dari $1 \mathrm{~cm}$ dimiliki oleh spesies Citrus amblycarpa, Citrus hystrix, dan Citrus nobilis. Lebar mahkota 0,1-0,5 dimiliki oleh semua jenis spesies kecuali Citrus maxima. Lebih lanjut, untuk jumlah benang sari 16-30 dimiliki oleh 5 spesies jeruk kecuali Citrus amblycarpa dan Citrus nobilis.

Parameter selanjutnya berjumlah 22, digunakan untuk mengidentifikasi buah. Adapun parameter yang diamati adalah bentuk, warna, permukaan, karakteristik kulit dan daging, panjang, kerekatan, jumlah segmen dan jumlah biji buah. Bentuk buah bulat gepeng dimiliki oleh spesies Citrus reticulata, Citrus nobilis, dan Citrus sinensis. Sedangkan tiga spesies lainnya memiliki bentuk buah bulat. Ratarata ukuran panjang buah ke 4 spesies adalah berkisar 1-5 $\mathrm{cm}$ dengan, namun ada pula spesies yang memiliki ukuran panjang berkisar 6-10 cm yaitu pada spesies Citrus reticulata, Citrus maxima, Citrus sinensis.

Buah yang berwarna hijau dimiliki oleh spesies Citrus amblycarpa, Citrus hystrix, dan Citrus aurantifolia, sedangkan 4 spesies lainnya memiliki warna buah hijau kekuningan. Permukaan buah kasar dan berdaging tebal dimiliki oleh spesies Citrus reticulata, Citrus amblycarpa, dan Citrus hystrix. Sedangkan spesies yang memiliki buah dengan permukaan halus dengan kulit tipis dimiliki oleh Citrus nobilis, Citrus senensis, dan Citrus aurantifolia, Akan tetapi untuk spesies Citrus maxima memiliki permukaan halus dengan kulit yang tebal.

Spesies Citrus reticulata, Citrus nobilis, Citrus maxima memiliki jumlah segmen buah sekitar 5-11, sedangkan Citrus amblycarpa, Citrus hystrix, Citrus sinensis, dan Citrus aurantifolia memiliki jumlah segmen sekitar 12-20 buah. Buah yang memiliki kerekatan lemah dimiliki oleh spesies Citrus reticulata, Citrus nobilis, dan Citrus sinensis, sedangkan jenis yang lainnya memiliki kerekatan yang kuat.

Lebih lanjut untuk warna daging buah pada suku jeruk-jerukan adalah putih krem dan oranye. Warna oranye dimiliki oleh spesies Citrus reticulata, Citrus amblycarpa, Citrus nobilis, dan Citrus 
sinensis. Sedangkan sisanya memiliki warna buah putih krem. Selain warna buah, Suku jeruk-jerukan juga memiliki rongga buah dan biji. Rongga buah ditemukan pada spesies Citrus abmlycarpa, Citrus hystrix, dan Citrus aurantifolia. Sedangkan jumlah biji 5-13 dimiliki oleh seluruh spesies kecuali Citrus amblycarpa dan Citrus nobilis yang memiliki jumlah biji sekitar 14-21. Parameter terakhir adalah pengamatan terhadap stomata. Berdasarkan hasil pengamatan penelitian ditemukan bahwa 7 spesies jeruk di Bener Meriah memiliki bentuk stomata yang sama, yaitu berjenis anomosytic.

\section{B. Hubungan Kekerabatan 7 Spesies Jeruk Di Dataran Tinggi Bener Meriah}

Penentuan kekerabatan tanaman dapat dilakukan dengan pengukuran Indeks Similaritas (IS) dan Indeks Dissimilaritas (ID). Nilai ID dapat ditentukan dengan menggunakan rumus ID $=$ IS-100. Selanjutnya, tingkat kekerabatan kelompok tumbuhan dianalisis dengan menggunakan analisis cluster (Hasan \& Fitri, 2014: 204).

Analisis cluster merupakan analisis yang mengelompokkan tumbuhan yang memiliki karakteristik yang sama sebagai objek penelitian. Hal ini bertujuan agar data dapat diringkas dan disajikan dalam bentuk dendogram (Sitepu dkk., 2011) Analisis cluster terbagi atas dua metode, yaitu metode hierarki dan metode non hierarki, akan tetapi dalam penelitian ini metode yang digunakan adalah metode hierarki yang mana pengelompokan dimulai dari kombinasi spesies yang memiliki nilai indeks similaritas lebih kecil.

Berdasarkan hasil analisis cluster yang dilakukan terhadap 7 spesies jeruk di daerah Bener Meriah, menunjukkan bahwa jumlah Indeks similaritas yang tinggi dimiliki oleh kombinasi spesies Citrus Hystrix dan Citrus aurantifolia dengan nilai IS sebesar 66. Djufri (2003: 34) berpendapat bahwa semakin tinggi suatu nilai dari Indeks similaritas maka semakin dekat hubungan kekerabatan yang dimiliki oleh kelompok tumbuhan tersebut, dan sebaliknya semakin rendah nilai similaritas maka semakin jauh kekerabatan dari kelompok tumbuhan tersebut. Adapun hasil analisis dari Indeks similaritas (IS) dan Indeks dissimilaritas (IDE) dari 7 spesies jeruk di Bener Meriah dapat dilihat pada Tabel 1 berikut:

Tabel 1 Hasil Perhitungan Indeks Similaritas (IS) dan Indeks Dissimilaritas

\begin{tabular}{|l|l|l|l|l|l|l|l|}
\hline & $\mathrm{A}$ & $\mathrm{B}$ & $\mathrm{C}$ & $\mathrm{D}$ & $\mathrm{E}$ & $\mathrm{F}$ & $\mathrm{G}$ \\
\hline $\mathrm{A}$ & & $47^{*}$ & $60^{*}$ & $46^{*}$ & $49^{*}$ & $47^{*}$ & $72^{*}$ \\
\hline $\mathrm{B}$ & 53 & & $46^{*}$ & $56^{*}$ & $88^{*}$ & $52^{*}$ & $60^{*}$ \\
\hline $\mathrm{C}$ & 40 & 54 & & $76^{*}$ & $43^{*}$ & $57^{*}$ & $34^{*}$ \\
\hline $\mathrm{D}$ & 54 & 44 & 24 & & $58^{*}$ & $43^{*}$ & $64^{*}$ \\
\hline $\mathrm{E}$ & 51 & 12 & 57 & 42 & & $59^{*}$ & $55^{*}$ \\
\hline $\mathrm{F}$ & 53 & 48 & 43 & 57 & 41 & & 48 \\
\hline $\mathrm{G}$ & 28 & 40 & 66 & 36 & 45 & 52 & \\
\hline
\end{tabular}


Keterangan

A :Citrus reticulata

B : Citrus amblycarpa

C : Citrus hystrix

D : Citus nobilis

E : Citrus maxima

$\mathrm{F} \quad$ : Citrus sinesis

$\mathrm{G}$ : Citrsu aurantifolia

Tabel 1 menunjukkan hubungan kekerabatan sangat dekat antara spesies Citrus hystrix dengan Citrus aurantifolia yaitu sebesar 66 selanjutnya di urutan kedua dimiliki oleh Citrus hystrix dengan Citrus maxima, dan Citrus nobilis dengan Citrus sinensis. Hubungan kekerabatan dengan indeks dissimilaritas tinggi dimiliki oleh kombinasi spesies Citrus amblycarpa dengan Citrus maxima yaitu sebesar 88 . Adapun bentuk dendogram yang dihasilkan dari analisis cluster untuk 7 spesies jeruk di Bener Meriah direpresentasikan dalam Gambar 1 berikut.

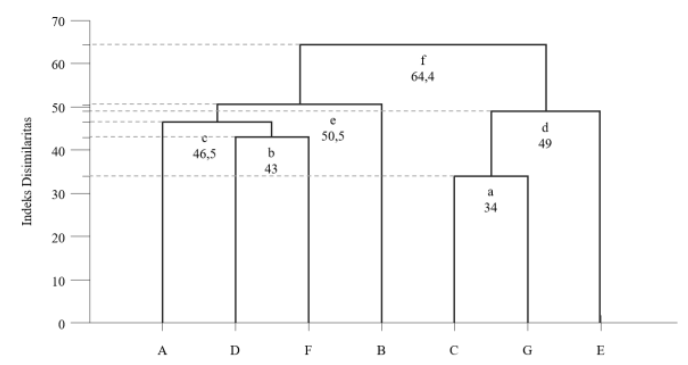

Gambar 1 Kekerabatan Fenetik 7 Spesies Jeruk Berdasarkan Karakteristik Morfologi Batang, Daun, Buah, dan Bunga.

Keterangan
A :Citrus reticulata
B : Citrus amblycarpa
C : Citrus hystrix
D : Citus nobilis

\section{$\mathrm{E} \quad$ : Citrus maxima \\ $\mathrm{F} \quad$ : Citrus sinesis \\ G : Citrsu aurantifolia}

Berdasarkan hasil analisis cluster nilai indeks dissimilaritas (Gambar 4.1), dapat dikelompokkan menjadi 6 kelompok, yaitu kelompok a terdiri dari spesies $\mathrm{C}$ dan $\mathrm{G}$ dengan nilai ID (Indeks dissimilaritasnya) yaitu 34; kelompok b spesies $\mathrm{D}$ dan $\mathrm{F}$ dengan nilai ID 43; kelompok c spesies A, D, F dengan ID 46; kelompok d spesies C, G, E dengan ID 49 ; kelompok e terdiri dari spesies A, D, F, B, dengan ID 50 dan kelompok $\mathrm{f}$ terdiri dari spesies A, D, F, B, C, G, E dengan ID 64.

Dendogram pada gambar 4.1 menunjukkan bahwa Citrus hystrix (C) dan Citrus aurantifolia (G) memiliki hubungan kekerabatan yang paling dekat, dimana kedua spesies ini memiliki ID (34) dan IS (66). Pasangan ini memiliki kesamaan pada 17 karakter morfologinya, yaitu memiliki duri pada batang, warna cabang hijau tua, adanya sayap daun, lebar daun 1-4 cm, tepi daun beringgit, memiliki sayap pada tangkai daun, bentuk buah bulat, buah berwarna hijau, warna daging buah putih krem, tidak memiliki rongga buah, panjang buah 1-5 cm, jumlah segmen buah 12-20, jumlah biji 5-13, kerekatan buah kuat, jumlah kelopak 4, jumlah mahkota 4, lebar mahkota $0,1-0,5 \mathrm{~cm}$, jumlah benang sari lebih dari 16. 
Kelompok kedua, yaitu Citrus nobilis (D) dan Citrus sinensis (F), dengan ID (43) dan IS (57). Kedua spesies ini memiliki sejumlah kesamaan ciri morfologi, yaitu ukuran panjang daun kurang dari $10 \mathrm{~cm}$, ukuran lebar daun 5- 10 $\mathrm{cm}$, tepi daun bergerigi, tidak memiliki sayap pada tangkai daun.

Kelompok ketiga, yaitu Citrus reticulata (A), Citrus nobilis (D) dan Citrus sinensis (F) dengan ID (46,5) dan IS $(53,5)$. Kelompok tumbuhan ini memiliki kesamaan sebanyak 9 karakter yaitu, tepi daun bergerigi, tidak adanya sayap pada tangkai daun, bentuk buah bulat gepeng, warna buah hijau kekuningan, warna daging buah oranye, memiliki rongga buah, kerekatan buah lemah, letak bunga diketiak daun, lebar mahkota $0,1-0,5 \mathrm{~cm}$.

Kelompok ke- 4, yaitu Citrus hystrix (C), Citrus aurantifolia (G) dan Citrus maxima (E) dimana memiliki sejumlah kesamaan yaitu warna cabang hijau tua, memiliki sayap daun, adanya sayap pada tangkai daun, bentuk buah bulat, warna daging buah putih krem, jumlah biji 5 -13, kerekatan buah kuat, jumlah kelopak 4, jumlah mahkota 4 dan jumlah benang sari lebih dari 16.

Kelompok ke-5, yaitu Citrus reticulata (A), Citrus nobilis (D), Citrus sinensis (F) dan Citrus amblycarpa (B) memiliki kesamaan yaitu, tepi daun bergerigi, tidak adanya sayap pada tangkai daun, warna daging buah oranye, letak bunga diketiak daun dan lebar mahkota 0,1 $-0,5 \mathrm{~cm}$.

Terakhir adalah kelompok ke-6, yang terdiri atas Citrus reticulata (A), Citrus nobils (D), Citrus sinensis (F), Citrus amblycarpa (B), Citrus hystri (C), Citrus maxima $(\mathrm{G})$ dan Citrus aurantifolia (E). Kesamaan karakter dari kelompok ini adalah memiliki bentuk daun bulat telur dan tipe stomata anomosytic. Kelompok ini memiliki hubungan kekerabatan paling jauh dengan ID $(64,4)$ dan IS $(35,6)$. Kesamaan karakter morfologi terbanyak pada 7 spesies jeruk adalah memiliki bentuk daun bulat telur, memiliki tipe stomata anomosytic, dan akar tunggang.

Selain itu untuk hasil analisis nilai indeks similaritas dan dissimaliritas yang dilakukan, ditemukan bahwa hubungan kekerabatan yang tertinggi ditemukan pada kombinasi spesies Citrus hystrix dengan Citrus aurantifolia, dengan nilai IS sebesar 66 selanjutnya di urutan ke dua dimiliki oleh Citrus hystrix dengan Citrus maxima, dan Citrus nobilis dengan Citrus sinensis, yaitu nilai IS nya sebesar $0,57 \%$. Hubungan kekerabatan yang jauh dimiliki oleh kombinasi spesies Citrus amblycarpa dengan Citrus maxima yang mana nilai ID 
sebesar 88 disebabkan karena banyak nya perbedaan ciri ciri morfologi nya.

\section{KESIMPULAN}

Adapun kesimpulan dari hasil penelitian ini adalah sebagai berikut: 1) Pengamatan terhadap karakteristik morfologi menunjukan adanya perbedaan dan kesamaan antar spesies jeruk yang ditemukan di Kabupaten Bener Meriah; 2) Hubungan kekerabatan sangat dekat dimiliki oleh kombinasi spesies Citrus hystrix dengan Citrus aurantifolia yaitu sebesar 66 selanjutnya di urutan ke dua dimiliki oleh Citrus hystrix dengan Citrus maxima, dan Citrus nobilis dengan Citrus sinensis. Sedangkan hubungan kekerabatan dengan indeks dissimilaritas tinggi dimiliki oleh kombinasi spesies Citrus amblycarpa dengan Citrus maxima yaitu sebesar 88.

\section{SARAN}

Berdasarkan hasil penelitian yang telah diperoleh, peneliti memberikan saran bagi peneliti selanjutnya diharapkan dapat mengembangkan penelitian ini dengan ruang lingkup yang lebih luas.

\section{DAFTAR PUSTAKA}

Aak. 1994. Budidaya Tanaman Jeruk. Yogyakarta: Penerbit Kanisius.
Deptan. 2012. Kajian Umum Mengenai Tanaman Jeruk Avaliable at http://ditlin.

Holtikultura.go.id/jeruk_cvdp/jeru k01.htm diakses 10 Oktober 2017.

Djufri. 2003. Analisis Vegetasi Spermatophyta di Taman Hutan Raya (Tahura) Seulawah Aceh Besar. Jurnal Biodiversitas. Vol 4(1): 30-34

Gotto, H.E. 1982. Animal Taxonomy. New York: Edward Arnold Publisher.

Hasanuddin dan Fitriana. 2014. Hubungan Kekerabatan Fenetik 12 Spesies Anggota Familia Asteracea. Jurnal EduBio Tropika. Vol 2(2): 187250

Radford, A. E. 1986. Fundamental of Plants Systematic. New York: Harper \& Rowpublishers

Sitepu, R., Irmetlyana dan Gultom, B. 2011. Analisis Cluster Terhadap Tingkat Pencemaraan Udara Pada Sektor Industri di Sumatera Selatan. Jurnal Penelitian Sains, 14(3):1117.

Tjitrosoepomo, G. 2007a. Morfologi Tumbuhan. Yogyakarta: Gadjah Mada University press.

Tjitrosoepomo, G. 2007b. Taksonomi Tumbuhan. Yogyakarta: Gadjah Mada University press.

Wienfarid. Sejarah dan Riwayat Bener Meriah. http://wienfarid.blogspot.co.id/ $d i$ akses 30 November 2016. 